Ann. Génét. Sél. anim., 1981, 13 (2), 119-130

\title{
Different types of response to selection for sex ratio in the flour beetle Tribolium castaneum
}

\author{
Batia LAVIE (*) \& A. BEILES $(*)$ \\ The Department of Genetics \\ The Hebrew University of Jerusalem, Jerusalem, Israel
}

\begin{abstract}
Summary
In an attempt to investigate the genetic basis of sex ratio, three wild populations and a synthetic population assembled from beetles collected all over Israel, were employed in a two way selection program for high and for low sex ratio. Different types of response to selection have been demonstrated by the four populations, revealing different modes of inheritance. In the synthetic population the selection was successful. Of the three wild populations, the first did not respond to selection, the second responded in one replica but exhibited consistent negative response in the other replica and in the third population, both positive and negative responses were observed in the various lines. In the lines where selection for high proportion of females was successful (especially in the synthetic population) a small decrease in the number of offspring was observed, indicating the existence of deleterious genes. High proportion of females may be a consequence of X-linked deleterious genes. Therefore, the evidence for the existence of additive genetic variation for sex ratio does not come from the lines successfully selected for high proportion of females, but from the fact that of the successfully selected lines, about half were successful in achieving a high proportion of males.
\end{abstract}

\section{Introduction}

The mode of inheritance of sex ratio bears an interest both on basic and applied genetics. The way natural selection acts on sex ratio fascinated evolutionists from DARWIN, through FISHER (1930) who discussed the evolution of a gene that acts on the gamete level, to Trivers \& WiLlard (1973) who discussed parent-offspring conflict over the sex ratio involving both the gamete and the zygote level. For applied genetics, regardless of the level of gene action, the main interest rests in the possibility to change the sex ratio maximalizing the profits.

Differences in sex ratio inheritance between the populations may be accounted for by genetic differences accumulated during the period of isolation and serve as an indicator to the existence of genetic variability for sex ratio when the species is considered as a whole. Response to selection demonstrates the existence of additive genetic variability in the populations observed. Increase in the proportion of females

(*) Present address : The Institute of Evolution, University of Haifa, Haifa, Israel. 
may be explained also by the presence of a recessive sex-linked lethal in the foundation population, but a response to selection in both directions indicates the existence of additive genetic variability for sex ratio in natural populations. Genetic differences between lines accompanied by no response to selection indicates non-additive components in the genetic variance for sex ratio.

Sex is determined in Tribolium by a pair of sex chromosomes - the female being homogametic. In this study, a two-way selection for high and for low sex ratio (defined as the proportion of males) has been applied to three wild populations of the flour bettle Tribolium castaneum, as well as to a synthetic population assembled from beetles collected all over Israel.

\section{Material and methods}

(i) Genetic stocks. Selection was carried out independently in the following stocks of Tribolium castaneum : three wild populations from three different cities in Israel and named after them (Jaffa, Beer-Sheba and Rehovot), where all the beetles that gave rise to a stock were collected together in a food plant or a grain store. A synthetic population was established from beetles that were collected from all over Israel and had been maintained in the laboratory, in mass culture for several years, with frequent additions of new beetles collected in the wild.

(ii) Experimental conditions. All experiements were carried out in the dark, in a Conviron (Controlled Environments Inc.) incubator, at a temperature of $29^{\circ} \mathrm{C}$ and 70 p. 100 relative humidity. The medium used was whole wheat flour supplemented with $5 \mathrm{~g}$ brewers' yeast in $100 \mathrm{~g}$ flour.

(iii) Experimental procedure. The selection program included two replicas for each population. Each replica consisted of two opposed selection lines. Selection was carried out for 6 generations. The parental generation for all the replicas was obtained by pairing 10 day old males and females, which were sexed as pupae. All beetles were of identical age in order to exclude age influences suggested on theoretical grounds by CHARLESWORTH (1977) and encountered for humans by NoviTSKY \& KIMBall (1958) \& Teitelbaum (1972). Therefore, the number of pairs varied from case to case according to the number of parents of identical age that could be obtained. The number of pairs in each case is presented in table 1 .

Each pair was kept in a separate vial. After 18 days the parents were discarded and the progeny sexed as the larvae pupated. For each family the proportion of males was calculated and the probability of getting this proportion by chance was the criterion for selection. The parents of the next generation were from five families selected for their low probabilities of getting biased sex ratio by chance. When more than five families had a sex ratio with a probability lower than 0.05 , all the families with probabilities less than 0.05 were employed in the mating for the next generation of selection.

Exceptions to the above experimental design :

In replica $A$ of Jaffa population no high sex ration line could be started because all the familes showed a higher proportion of females. 
TABLE 1

The proportion of males and the standard error in the parental generation (In parenthesis - number of pairs whose progeny was observed)

La proportion des mâles (taux de masculinité) et l'erreur-standard dans la génération parentale (Entre parenthèses le nombre des couples dont la descendance a été observée)

\begin{tabular}{|c|c|c|c|c|c|}
\hline \multirow{2}{*}{ Population } & \multicolumn{3}{|c|}{ Repetitions } & \multicolumn{2}{|c|}{ Total } \\
\hline & Replica A & Replica B & Replica C & Males & Females \\
\hline Synthetic & (17) $.460 \pm .027$ & (13) $.504 \pm .031$ & (30) $.488 \pm .013$ & 1031 & 1091 \\
\hline Jaffa & (24) $.474 \pm .013$ & (28) $.488 \pm .013$ & & 1414 & 1526 \\
\hline Beer-Sheba & (25) $.529 \pm .015$ & (30) $.493 \pm .015$ & & 1136 & 1082 \\
\hline Rehovot & (25) $.497 \pm .011$ & (28) $.513 \pm .010$ & & 2340 & 2290 \\
\hline
\end{tabular}

In replica $\mathbf{B}$ of the synthetic population, the first generation for high sex ratio included only three familes and all with a higher proportion of females. The selection for high sex ratio in this line was therefore discontinued and a new replica established. The low sex ratio line of replica $B$ in the synthetic population, by the sixth generation attained the highest proportion of females observed throughout this selection program. Therefore, selection was continued for the seventh generation where there was no more improvement.

In replica $A$ of Beer-Sheba population, the selection for low sex ratio was discontinued, when it maintained for three consecutive generations a highly significant lower proportion of males without further improvement. For the high sex ratio line of this replica, only 5 generations of selection are presented because in the sixth generation, due to a technical error, 25 days elapsed before sexing the pupae and the majority of the progeny were already adults.

\section{Results}

Table 1 presents the data for the parental generation. A $\chi^{2}$ test was applied to compare differences between the distribution of males and females in the four populations. The value obtained $\left(\chi^{2}{ }_{3}=7.43\right)$ is slightly less than the critical value $\left(\chi_{3}^{2}=7.81\right)$ for the 0.05 level of significance.

Table 2 (a-d) summarizes for each line :

1) The proportion of males and the standard error in the selection lines throughout the selection experiment. Significant deviations from 0.5 are marked by astericks.

2) The number of families observed in each generation.

3) Proportion of negative responses. It summerizes the cases when the sex ratio changed in the direction opposite to selection. These generations are marked by an exclamation sign. 

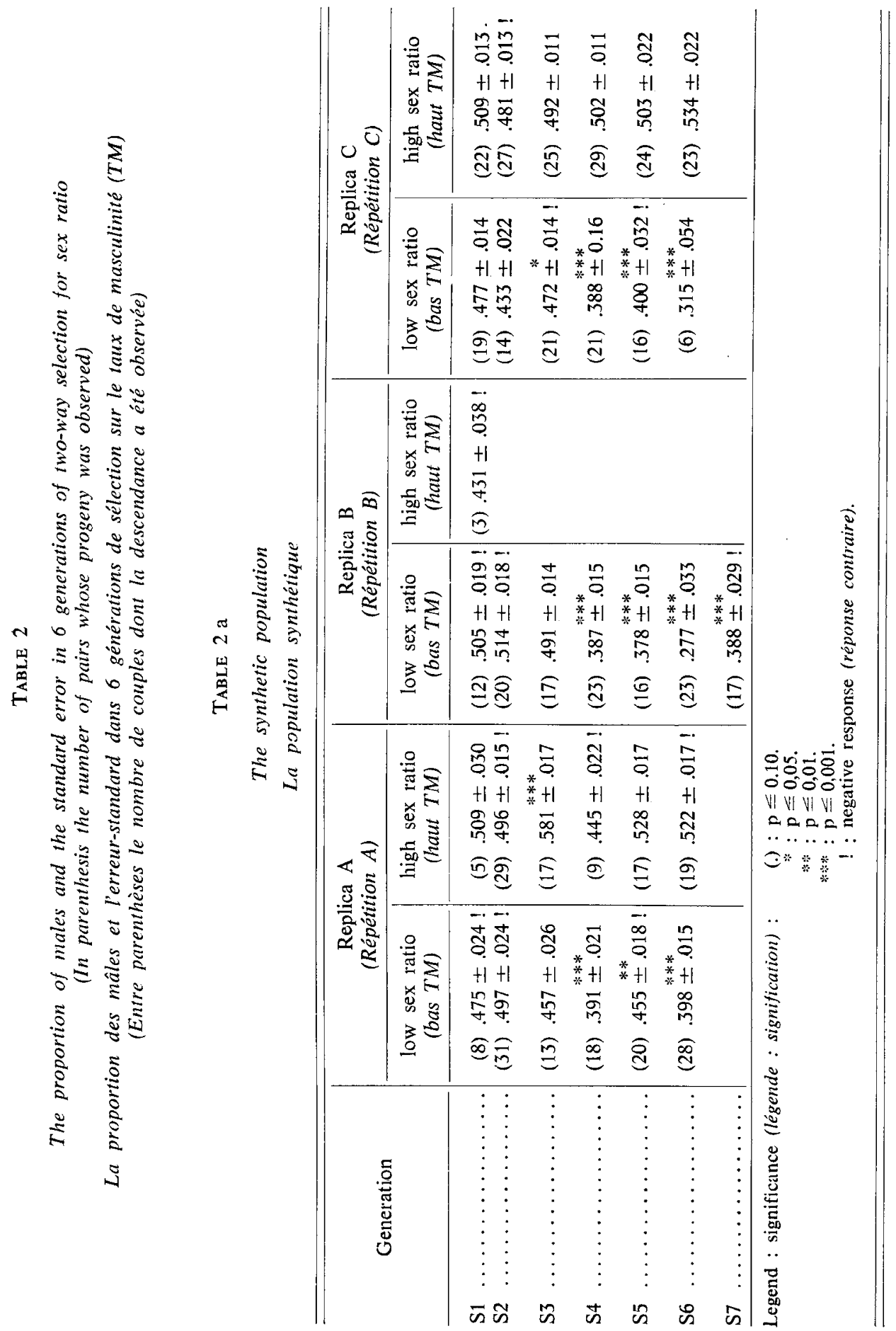


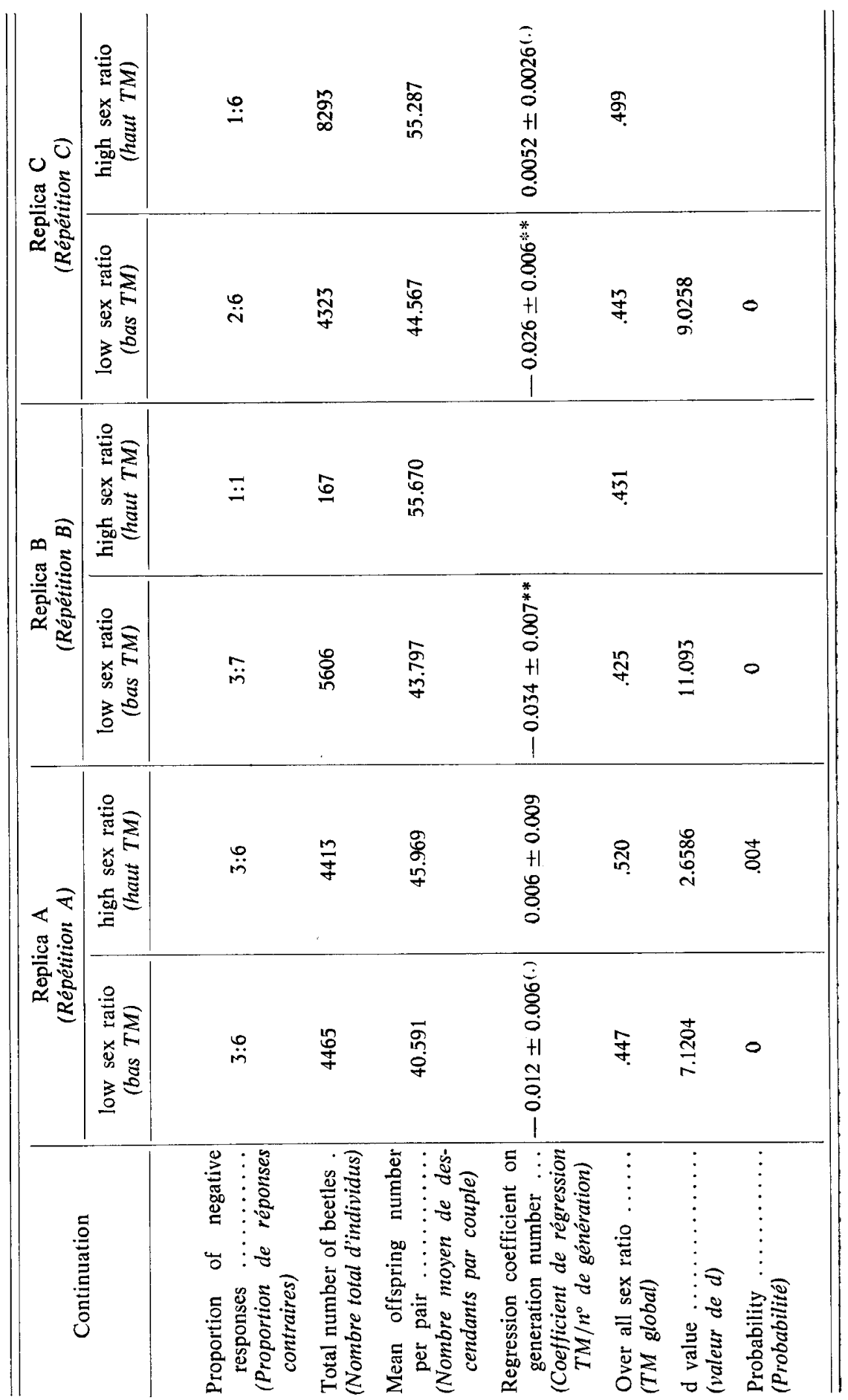




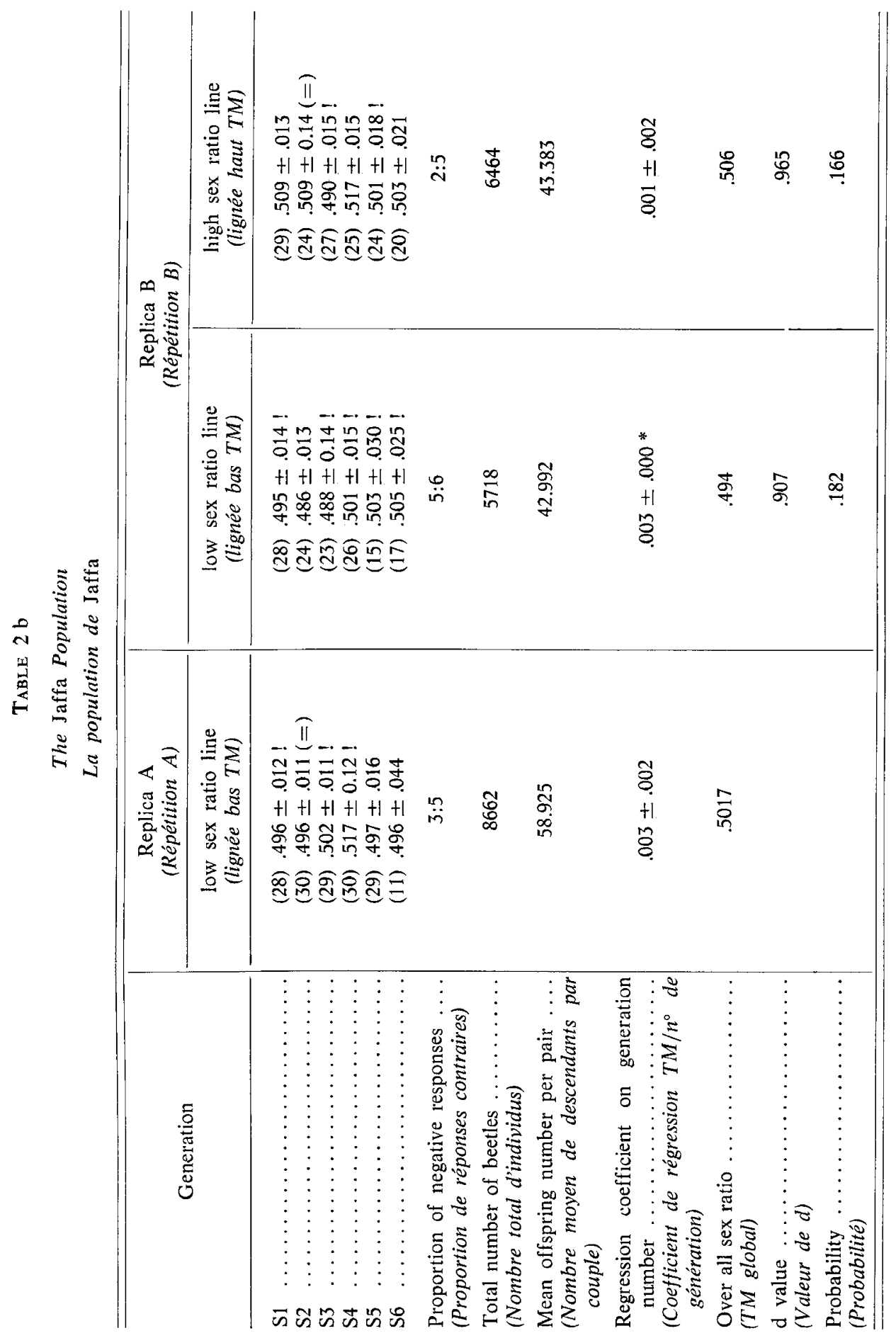




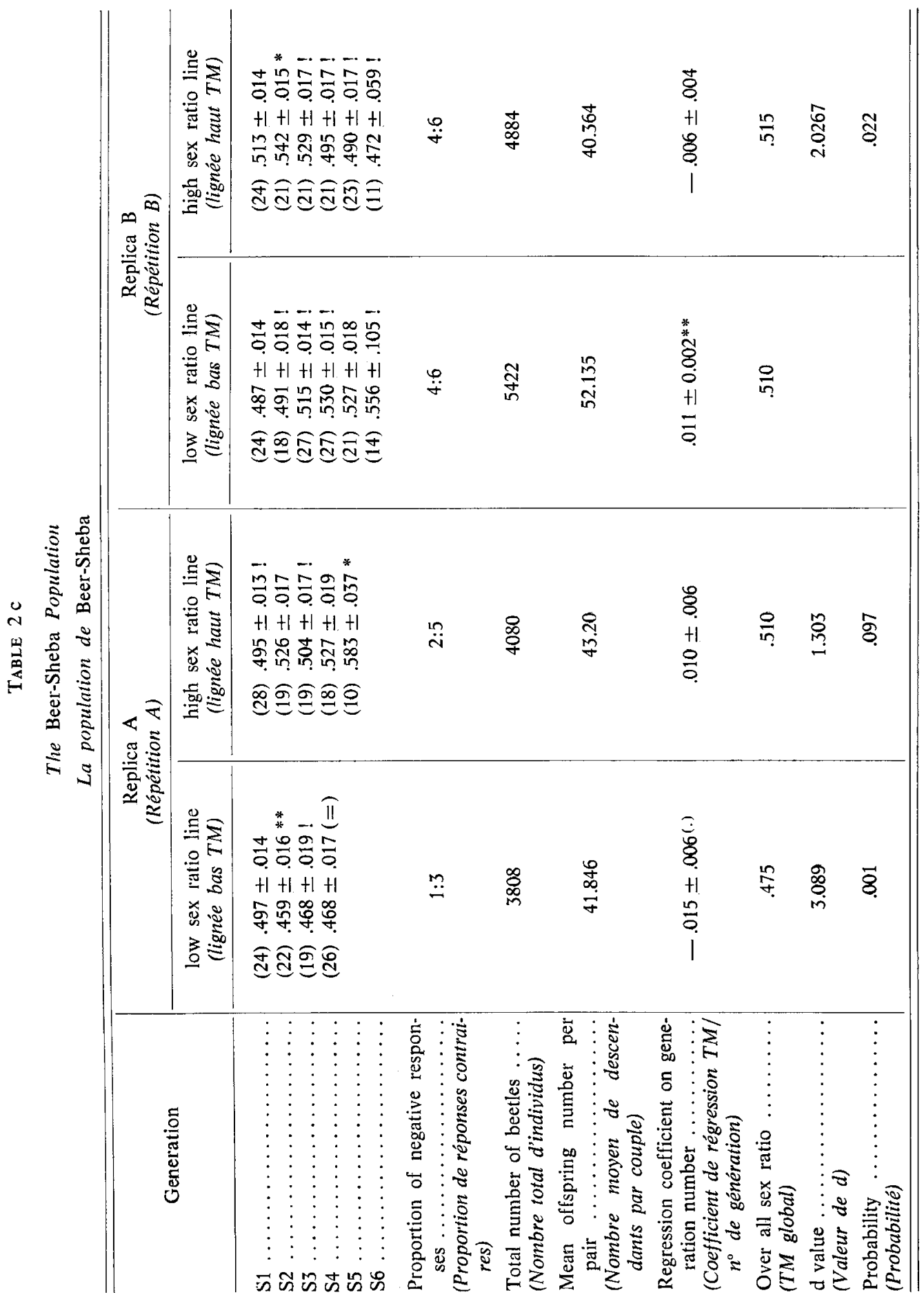




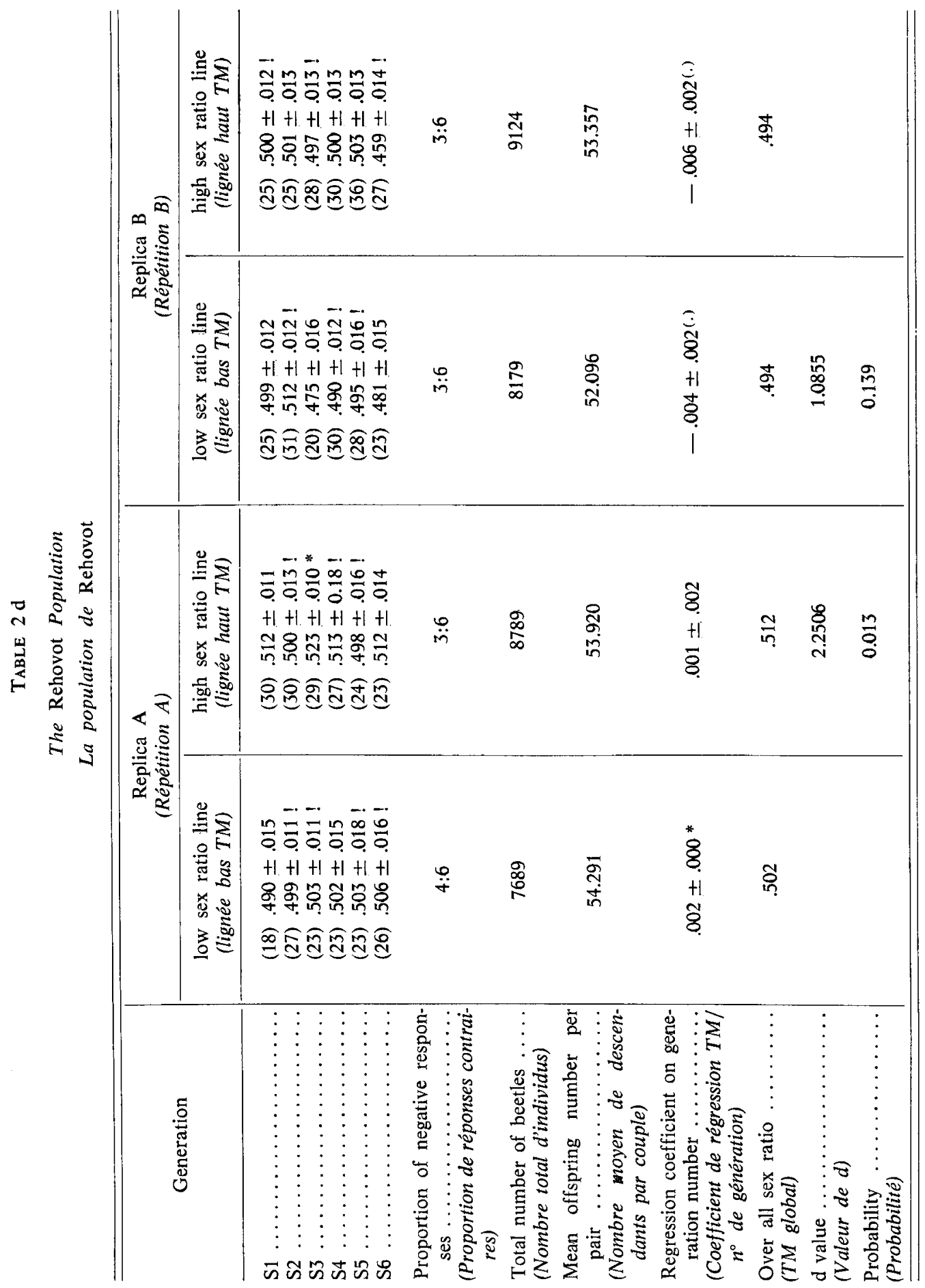


4) Total number of beetles.

5) Mean number of offspring per pair.

6) Regression coefficient of proportion of males on generations, and its standard error.

7) The sex ratio for the accumulated results.

8) d value obtained in the Balley (1959) test for proportions, in cases when the accumulated sex ratio deviates in the direction of selection.

9) The probability for the d value.

The four populations observed show three different responses to selection :

(1) Response to selection according to the additive genetic model as represented by the synthetic population (table 2 a) which being an assemblage of beetles collected all over the country is expected to possess the highest genetic variability, and by Beer-Sheba, replica $A$.

(2) Lack of response to selection indicating the absence of additive variation in the observed population as represented in the Jaffa population (table $2 \mathrm{~b}$ ).

(3) Consistent negative response to selection as observed in replica B of BeerSheba population (table $2 \mathrm{c}$ ), and the low line of replica B of Jaffa (table $2 \mathrm{~b}$ ).

In recording for each line the cases of negative response to selection throughout the generations, the negative response (which characterizes $\mathrm{X}$-linked inheritance) is evident both in lines where the selection was not successful and in the lines where selection succeeded.

In the lines where the selection was not successful (Jaffa, Beer-Sheba replica B and Rehovot) on the assumption of zero additive genetic variation the expected proportion of negative response is 0.5 . The observed value was 31 cases out of 42 responses $(\mathrm{p}=.001)$.

The opposing force to selection is felt also in the lines where selection was successful (Synthetic and Beer-Sheba, replica A) : 17 negative responses out of 40, when the expected value according to the additive model is low.

For all 4 lines where selection for low sex ratio succeeded, the mean offspring number per pair is less than in the opposed selected line (a feature conspicuous especially in the synthetic population). When there was a consistent negative response to selection as in replica B of Beer-Sheba population, the low selection line which attained a higher proportion of males had also a higher mean offspring number per pair than the parellel opposed line. This is indicating that X-linked deleterious genes were involved in this selection. This is also reflected by the fact that in most cases, the departure from 0.5 was higher in the low sex ration line than in the high sex ratio line. However, out of 7 lines where selection succeeded, 3 were for high sex ratio. This result overrules the possibility that the response to selection was due only to the deleterious $\mathrm{X}$-linked genes. The progress in the high sex ratio lines reflects the presence of additive genetic variation. 


\section{Discussion}

Previous attempts to find evidence for genetic variation in sex ratio brought ambiguous results. Higher female proportion obtained by selection has been reported for the parasite Dahebominus fuliginosus by WILKES (1947) and for Mastrus carpocrapsae by Simmonds (1947). RAM \& ShaRma (1977) were not successful in selecting sex ratio in Trichogramma fasciatum. A high proportion of females can be obtained also by the presence of a recessive sex-linked lethal or deleterious gene in the foundation population. Therefore, in order to prove the existence of additive genetic variation for sex ratio either the successful selection of the heterogametic sex or the possibility to overrule the existence of X-linked recessive lethals when the homogametic sex was successfully selected is necessary.

Analyzing and interpreting the data on the human species, EDWARDs (1970) came to the conclusion that there is no genetic variation for sex ratio. Falconer (1954) drew a similar conclusion from his experimental study of mice and Drosophila. Yet he pointed out that his experiments do not exclude the possibility that there is sufficient genetic variability for the sex ratio to enable natural selection to alter it in wild populations. His experiment suffered from the unavoidable difficulty that any measurement of the sex ratio in a family is subject to large sampling error, which may be sufficient to annihilate any real difference. This is the reason that in the two cases reporting genetic variability for sex ratio the problem of sampling error was reduced : (1) WEIR (1953) was able to produce a striking difference in the sex ratio of mice by selecting, not for the sex ratio itself, but for blood $\mathrm{pH}$. This is a consequence of the fact that when two characteristics are correlated, it may be easier to alter the trait with the enormous sampling error by selecting for the correlated trait unaffected by sampling error. However, the correlation between blood $\mathrm{pH}$ and sex ratio in Weir's experiment seems to have been accidental, perhaps because of linkage disequilibrium in the foundation population. When WEIR \& CLARK (1955) repeated the experiment, they again obtained a response in blood $\mathrm{pH}$, but this time there was no associated change in sex ratio. (2) BAR-ANON \& RoBERTson (1975) analyzed over 150,000 births sired by 107 bulls in domestic cattle. This huge amount of data enabled them to find significant difference between bulls as well as a significant correlation of 0.5 between the sex ratio from a bull and from the father of that bull.

The present selection program illustrates to a maximum, the controversial result reported by different investigations in respect to the success in selecting for sex ratio. Four populations of $T$. castaneum rendered three different types of response to selection ranking from successful response to consistent negative response. Bearing in mind that the selected characteristic is not measured on the individual, but is rather the consequence of the distribution of males and females in the observed family, it is highly probable that the sex ratio is determined by more than one inheritance mechanism. A successful response to selection may therefore be determined by several criteria : 1) Regression coefficient which reveals gradual advances as predicted by the polygenic model. 2) Accumulated sex ratio which is preferable in cases when all the advance was obtained in the first generations, as predicted when the variance involves only a few loci. 3) The significance of departure from 1:1 sex ratio in a single generation, which is important in cases when the response occurred in one of the last generations. The various results obtained are the consequence of the interaction between different mechanisms : 
1) An additive mechanism that uses the available additive genetic variation and increases gradually the proportion of the selected sex. An example for this mechanism is the synthetic population where the genetic variability is magnified by sampling from many gene pools. In this population, an overall positive response to selection is observed even though in some generations the opposing mechanism causes superimposed negative response.

2) Non additive inheritance that in spite of consistent (genetic) differences between lines, will not respond to selective pressures as in Jaffa population (although small negative responses predominate).

3) X-linked factors that influence sex ratio by affecting the viability of its bearer. If those factors are codominant, unequal distribution between the sexes will sometimes enhance the observed response and will cause negative response in the next generation. Such a negative response to selection is significant in both directions in replica B of Beer-Sheva, and mild in two low lines one of Rehovot and one of Jaffa.

The controversial results in the selection for sex ratio obtained not only between different species and investigations, but even when the same selection procedure is applied to various populations of the same organism complicates the prediction about the success of selection for sex ratio. However, it may be concluded that additive genetic variation for sex ratio exists at least in some populations and on these occasions it can be used by selection for the desired sex. This may be extremely important in animal husbandry in situations where from the economic point of view, a biased sex ratio is preferable. A program of mixing gene pools in order to reveal additive genetic variation may be justified. Another solution could be producing male and female lines, which differ in X-linked genes and when crossed accordingly, produce the desired sex ratio.

Received for publication in may 1981.

\author{
Résumé \\ Différents types de réponse à une sélection sur le taux de masculinité \\ chez Tribolium castaneum
}

Dans une recherche sur la base gẻnétique du taux de masculinité (TM), trois populations sauvages et une population synthétique de Tribolium, en provenance de toutes les régions d'Israël, ont été utilisées dans un programme de sélection pour élever et abaisser ce taux. Différents types de réponses à la sélection ont été obtenus dans les quatre populations et révèlent des modes différents de transmission héréditaire. Dans la population synthétique la sélection a été efficace. Parmi les trois populations sauvages, la première n'a pas répondu à la sélection, tandis que la deuxième a répondu dans l'une des répétitions mais a donné des réponses toujours contraires dans les autres répétitions. Quant à la troisième population, selon les lignées des réponses favorables ou contraires ont été obtenues. Dans les lignées où la sélection a permis d'abaisser le TM (particulièrement dans la population synthétique) une légère diminution du nombre de descendants a été observée, ce qui indique l'existence de gènes défavorables. Une proportion élevée de femelles peut en effet être la conséquence des gènes défavorables liés au chromosome $X$. C'est pourquoi la preuve de l'existence d'une variation génétique additive pour le TM ne vient pas des lignées sélectionnées avec succès pour diminuer ce taux mais du fait que, parmi les lignées qui ont répondu favorablement à la sélection, environ la moitié ont manifesté un accroissement de la proportion des mâles. 


\section{References}

BaIley N.J.J., 1959. Statistical methods in biology. English University Press, London, pp. 38-39.

BAR-ANON R., ROBERTSON A., 1975. Variation in sex ratio between progeny groups in dairy cattle. Theor. appl. Genet., 46, 63-65.

Charlesworth B., 1977. Population genetics, demography and the sex ratio. In: Measuring Selection in Natural Population, ed. F.B. Christiansen and T.M. Fenchel, pp. 345-363. Berlin, Springer-Verlag.

EJWards A.W.F., 1970. The search for genetic variability of the sex ratio. J. biosoc. Sci. Suppl., 2, 55-60.

FAlConer D.S., 1954. Selection of sex ratio in mice and Drosophila. Am. Nat., 88, 385-397.

Fisher R.A., 1930. The General Theory of Natural Selection. Oxford University Press.

Novitski E., Kimball A.W., 1958. Birth order, parental ages and sex of offspring. Am. J. hum. Genet., 21, 123-131.

Ram A., Sharma A.K., 1977. Selective breeding for improving the fecundity and sex ratio of Trichogramma fasciatum (perkins) (Trichogrammatidae : Hymenoptera), an egg parasite of Lepidopterous hosts. Entomon, 2, 133-137.

Simmonds F.J., 1947. Improvement of the sex ratio of parasite by selection. Can. Entomol., 79, 41-44.

Teitelbaum M.S., 1972. Factors associated with the sex ratio in human populations. In: The structure of Human populations, eds. G.A. Harrison and A.J. Boyce, pp. 90-109. Oxford University Press.

Trivers R.L., Willard D.E., 1973. Natural selection of parental ability to vary the sex ratio of offspring. Science, $179,90-92$.

WeIR J.A., 1953. Association of blood-pH with sex ratio in mice. I. Hered., 44, 133-138.

Weir J.A., Clark R.D., 1955. Production of high and low blood-pH lines of mice by selection with inbreeding. J. Hered., 46, 125-132.

Wilkes A., 1947. The effect of selective breeding on the laboratory propagation of insect parasites. Proc. r. Soc., 134 B, 221-245. 